\title{
Dietary Effect of Eicosapentaenoic Acid (EPA) Containing Soyphospholipid
}

\author{
Sayantani Dasgupta ${ }^{1}$ and Dipak Kumar Bhattacharyya ${ }^{2 *}$ \\ ${ }^{1}$ Berhampore Girls' College, Berhampore, Murshidabad, West Bengal, INDIA \\ ${ }^{2}$ Department of Chemical Technology, University of Calcutta, University Colleges of Science \& Technology, 92, A.P.C. Road, Kolkata \\ 700009, INDIA
}

\begin{abstract}
In this study, we evaluated on a comparative basis the dietary effect between eicosapentaenoic acid (C20:5, EPA)- containing soyphospholipid and soyphospholipid without EPA when added at 5\% or $10 \%$ level by weight in soybean oil as the dietary oil on the proportions of lipid components in serum of rats. Rats were taken in five groups. One group was fed $20 \%$ soybean oil. Two groups received soybean oil containing $\mathbf{5 \%}$ and $\mathbf{1 0 \%}$ soyphospholipid by weight, respectively. Two other groups were fed soybean oil containing $5 \%$ and $10 \%$ EPA-containing soyphospholipid by weight, respectively. The other dietary components remained same for all the groups. The feeding experiment was conducted for 4 weeks. After the feeding period there was no significant change in weight gain, food intake and food efficiency ratio (FER). No significant change was observed in serum lipid profiles between the rats fed soybean oil and soybean oil with $5 \%$ or $10 \%$ soyphospholipid. There was significant decrease in serum triglyceride (TG) level in the rats fed soybean oil blended with EPA containing soyphospholipid at $5 \%$ level. The contents of total cholesterol (TC), TG, very low density lipoprotein (VLDL)-cholesterol and low density lipoprotein (LDL)-cholesterol decreased significantly while high density lipoprotein (HDL)-cholesterol increased compared to the soyphospholipid group at $10 \%$ level.
\end{abstract}

Key words: EPA, soyphospholipid, soybean oil

\section{INTRODUCTION}

The nutritional and biochemical role of phospholipids are well known. Phospholipids are surface active agents and they are found in all living cells of animal or plant origin. In humans and in animals phospholipids are concentrated in the vital organs such as brain, liver and kidney; in vegetables they are highest in the seeds, nuts and grains. As constituents of plasma membrane and active participants in metabolic processes, they are essential to life. Phospholipids that are commonly ingested through vegetable oils have distinct composition pattern displaying in turn their effects on membrane structure and serum lipid profile. Phospholipids are also believed to be hypocholesterolemic agents. Lecithin decreases low density lipoprotein (LDL) cholesterol and increases high density lipoprotein (HDL) cholesterol in serum and may also suppress intestinal cholesterol absorption ${ }^{1)}$. It is known that the molecular nature of the phospholipids of vegetable oils (e.g.
Soybean oil) can be modified by altering their fatty acid profiles by short chain, medium chain and higher polyunsaturated fatty acids (PUFAs) $)^{2)}$. The effects of such types of modified phospholipids on lipid profiles of membranes, serum and other tissues are likely to be different from the phospholipids having normal fatty acid profiles like saturated and unsaturated individual fatty acids.

Phospholipids with specific fatty acid compositions can sometimes be obtained by fractionation of natural phospholipids but the most common approach is to synthesize the desired compounds by replacing the existing fatty acids with the desired ones by the process of reesterification or interesterification ${ }^{3)}$. Enzymatic synthesis methods, which are characterized by mild reaction conditions and high selectivity, can be expected to be of great importance in the modification of phospholipid. The group of enzymes that are most likely to catalyze transesterifications of phospholipids are the phospholipases. Phospholipase A1

*Correspondence to: Dipak Kumar Bhattacharyya, Department of Chemical Technology, University of Calcutta, University Colleges of Science \& Technology, 92, A.P.C. Road, Kolkata 700009, INDIA

E-mail: dkb_oiltech@rediffmail.com

Accepted July 24, 2007 (received for review May 22, 2007)

Journal of Oleo Science ISSN 1345-8957 print / ISSN 1347-3352 online

http://jos.jstage.jst.go.jp/en/ 


\section{S. Dasgupta and D.K. Bhattacharyya}

and $\mathrm{A} 2$ are specific for the hydrolysis of the fatty acids in the sn- 1 and sn-2 positions respectively. Other lipases, which in general are either nonspecific or are specific for the sn- 1 and sn- 3 positions may also be useful in phospholipid modifications.

The phospholipids monoester interchange reaction with the help of a specific lipase also can be utilized in fortifying phospholipids in their fatty acid profile at the 1-position. By this type of ester-ester interchange, it may be possible to introduce a specific fatty acid molecule in the phospholipids moiety. The advantage of using 1,3-specific lipases for transesterification of phospholipids is to protect the natural fatty acid composition in the 2-position which is mainly enriched with the unsaturated fatty acids.

A report of lipase catalyzed regiospecific 1-position (1pos) transesterification of fatty acids in phosphatidylcholine (PC) and phosphatidylethanolamine (PE) was made by Brockerhoff et $a l^{4)}$.

It is known that certain PUFA such as eicosapentaenoic acid (EPA) and docosahexaenoic acid (DHA) which are biologically active substances inhibit platelet aggregation and prevent cerebral thrombosis and arterial sclerosis have attracted attention. So phospholipids containing these PUFA might have better results than the original one and for this reason the physiological activity of fish phospholipids that are rich in PUFA has attracted much attention $^{5}$. It has been reported that PUFA containing PC at sn-2 position can be more easily digested by the body than any other positional isomers and might be of value in nutritional and medical applications ${ }^{6}$. Magret et al. ${ }^{7)}$ reported that the sn-2 PUFA containing PC is a major source of entry of PUFA into the brain. $\mathrm{Na}$ et $a l^{6}{ }^{6}$ suggested that phosphatidylcholine esterified with EPA or DHA at the sn2 position could be more easily digested in the body and might be of value in nutritional and medical applications. Yoshimoto et $a l^{8)}$ used polyethelene-glycol-modified Candida cylindracea lipase dissolved in benzene to incorporate PUFAs into PC. Totani and Hara ${ }^{5}$ ) also used a water/oil system but used sardine oil as source of PUFAs for incorporation into soyphospholipid.

PUFAs like EPA and DHA are known for their beneficial effects in influencing the lipid profiles of serum and other tissues and accordingly have attracted attention to produce phospholipids containing these PUFA. The aim of the present study is to evaluate the dietary effect of EPA- containing soyphospholipid on the proportions of lipid components such as total cholesterol (TC), low density lipoprotein (LDL) - cholesterol, high density lipoprotein (HDL) cholesterol, very low density lipoprotein (VLDL) - cholesterol, triglyceride (TG)] of serum compared to dietary soyphospholipid without EPA along with soybean oil as the dietary oil.

\section{EXPERIMENTAL}

\subsection{Materials}

Soybean Oil: Soybean oil branded name Aadhaar, manufactured and packed by Acalmar Oils and Fats Limited, Hyderabad, India was used as a dietary oil.

Soyphospholipids: Soyphospholipids used in this study was supplied by V.P.Industries M.P. India.

Fatty Acids: Ethyl ester of EPA was a generous gift of Soken Chemical and Engineering Co.Ltd, 29-5 Takada 3Chome, Toshima-Ku, Tokyo 171-8531, Japan.

Chemicals and solvents: Except otherwise specified, all chemicals and solvents were purchased from S.D.Fine Chemicals (India) Ltd

\subsection{Experimental procedures}

Deoiling of soyphospholipid ${ }^{9}$ : Crude soyphospholipid was deoiled by repeated acetone treatment. Acetone (in 1:7 $\mathrm{w} / \mathrm{v})$ ratio was added to phospholipids and the solution was allowed to stand at $4^{\circ} \mathrm{C}$ for 2 hours. The solution was filtered and the acetone solution was distilled to isolate acetone. This treatment was repeated until the acetone layer was colourless. The acetone insoluble fraction which contains phospholipids was carefully dried. With the supplied soyphospholipid, the yield of deoiled phospholipids was about 54\%.

Soyphospholipid-Monoester Interchange Reaction by Lipase: Soyphospholipid and ethyl ester of fatty acid in 1:5 molar ratio (to solubilise the soyphospholidid) were taken in a $50 \mathrm{ml}$ round bottomed flask and stirred by a magnetic stirrer at $60 \pm 2^{\circ} \mathrm{C}$ for 10 days by using $15 \%$ (by weight of the reactants) of Mucor miehei lipase (lipase initially contains $10 \% \mathrm{w} / \mathrm{w}$ water).The product was analyzed at definite time interval and finally after 10 days incubation the product mixture was filtered to remove the enzyme. Transesterified phospholipid was isolated by separation from the mixed ethyl esters of fatty acid by extraction with acetone.

\subsection{Analysis of fat products}

Gas-liquid chromatography was employed for determination of fatty acid composition of the methyl esters of component fatty acids of soybean oil and soyphospholipids after their conversion into methyl esters by $\mathrm{BF}_{3}$ methanol ${ }^{10)}$.

\subsection{Preparation of dietary fat}

Blending of soyphospholipid as such and EPA containing soyphospholipid with the soybean oil was done at the level of $5 \%$ and $10 \%$.

\subsection{Feeding experiment}

Experimental animals and diets: The animal experiment was designed based on earlier reports ${ }^{11}$. Male Albino rats (Charles Foster Strain) weighing an average of $60 \mathrm{~g}$ were housed individually in stainless steel cages with mesh floors in a room maintained under constant temperature 
$\left(20-25^{\circ} \mathrm{C}\right)$ and a $10 \mathrm{~h} \mathrm{light} / 14 \mathrm{~h}$ dark cycle. Following 10 day adaptation during which the animals were maintained on a standard diet ${ }^{11)}$ and water ad libitum, rats were divided into five groups of 8 rats per group. Soybean oil and soybean oil blended with soyphospholipid at 5\% and 10\% level were taken as control and the other two groups were kept as experimental (soybean oil blended with EPA containing soyphospholipid at $5 \%$ and $10 \%$ level). The feeding experiment was carried out for four weeks. Food intake was measured daily while growth of the animals was monitored once a week.

Each group of rat fed different dietary oil while the other dietary components were same. Carbohydrate was supplied by corn starch (I.P. grade) which contributed 55\% of the diet $18 \%$ of the diet derived from casein, cellulose which contributed to $3 \%$ of the diet. $4 \%$ of the diet was derived from ash, which was supplied by mineral mixture, (composition of mineral mixture No.12 (in g): $\mathrm{NaCl} 292.5$, $\mathrm{KH}_{2} \mathrm{PO}_{4}$ 816.6; $\mathrm{MgSO}_{4}$ 120.3; $\mathrm{CaCO}_{3}$ 800.8; $\mathrm{FeSO}_{4}, 7 \mathrm{H}_{2} \mathrm{O}$ 56.6; KI 1.66; $\mathrm{MnSO}_{4}$. $2 \mathrm{H}_{2} \mathrm{O}, 9.35 ; \mathrm{ZnCl}_{2} 0.5452 ; \mathrm{CuSO}_{4}$. $5 \mathrm{H}_{2} \mathrm{O}$, 0.9988, $\left.\mathrm{CoCl}_{2} 6 \mathrm{H}_{2} \mathrm{O} 0.0476\right)^{12)}$. Total $20 \%$ fat and $0.01 \mathrm{~g}$ of vitamin capsule (Vitamin A I.P. 10000 units, Thiamine mononitrate I.P. $5 \mathrm{mg}$, Vitamin B I.P. $5 \mathrm{mg}$, Calcium pantothenate USP $5 \mathrm{mg}$, Niacinamide I.P. $50 \mathrm{mg}$, Ascorbic acid I.P. 400 units, Cholecalciferol USP 15 units, Menadione I.P. $9.1 \mathrm{mg}$, Folic acid I.P.1mg, Vitamin E USP $0.1 \mathrm{mg}$ ) were also included in the diet.

The Food Efficiency Ratio (FER) for each rat was calculated by the following equation.

FER = Body weight gain / Food consumed.

At the end of 4 weeks experimental period, $14 \mathrm{~h}$ fasted rats were subjected to a light anaesthesia using chloroform. The abdomen was opened, blood samples were collected from the hepatic vein in the presence of heparin and centrifuged at low speed $(3000 \times \mathrm{g})$ to isolate the plasma.

\subsection{Lipid analysis}

According to the standard enzymatic methods, the lipid components such as $\mathrm{TC}^{13)}$, $\mathrm{HDL}^{14)}$, $\mathrm{LDL}^{15)}$, $\mathrm{VLDL}^{16)}$ and $\mathrm{TG}^{17)}$ of the plasma were determined.

\subsection{Statistical analysis}

Data from the nutrition study were analysed using the student ' $\mathrm{t}$ ' test ${ }^{18)}$. Significance was accepted at $\mathrm{p} \leq 0.05$.

\section{RESULTS}

\subsection{Fatty acid composition}

The fatty acid composition of soybean oil, soyphospholipid and EPA containing soyphospholipid are shown in Table 1.

\subsection{Growth rate}

Figures 1 and 2 indicate the growth response and the FER of rats fed soybean oil, soybean oil blended with soyphospholipid at 5\% and 10\% level and soybean oil blended with EPA containing soyphospholipid at 5\% and 10\% level. These figures indicate that there is no significant change in growth response and FER of the experimental group in comparison with the control group.

\subsection{Lipid profile}

Table 2 shows the plasma TC, TG, HDL, LDL and VLDL level of rats fed soybean oil, soybean oil blended with soyphospholipid at the level of $5 \%$ and $10 \%$ and soybean oil blended with EPA containing soyphospholipid at the level of $5 \%$ and $10 \%$. There is no significant change in the plasma lipid profile among the rats fed soybean oil and soybean oil blended with soyphospholipid at the level of 5\% and $10 \%$. There is significant decrease in TG level in case of the rats fed soybean oil blended with EPA containing

Table 1 Fatty Acid Composition of Soybean Oil, Soyphospholipid, Eicosapentaenoic Acid (20:5n-3, EPA) Containing Soyphospholipid.

\begin{tabular}{|l|c|c|c|}
\hline \multirow{2}{*}{\multicolumn{1}{|c|}{ Fatty Acids }} & Soybean Oil & Soyphospholipid & $\begin{array}{c}\text { Soyphospholipid } \\
\text { containing EPA }\end{array}$ \\
\cline { 2 - 4 } & 10.5 & 25.7 & 19.6 \\
\hline Palmitic acid (16:0) & 4.4 & 2.9 & 2.4 \\
\hline Stearic acid (18:0) & 21.6 & 14.7 & 11.7 \\
\hline Oleic acid (18:1) & 54.7 & 52.5 & 44.5 \\
\hline Linoleic acid (18:2) & 8.8 & 4.2 & 2.6 \\
\hline $\begin{array}{l}\text { Linolenic acid } \\
(18: 3)(n-3)\end{array}$ & - & & 18.4 \\
\hline $\begin{array}{l}\text { Eicosapentaenoic acid } \\
(20: 5)\end{array}$ & & & \\
\hline
\end{tabular}




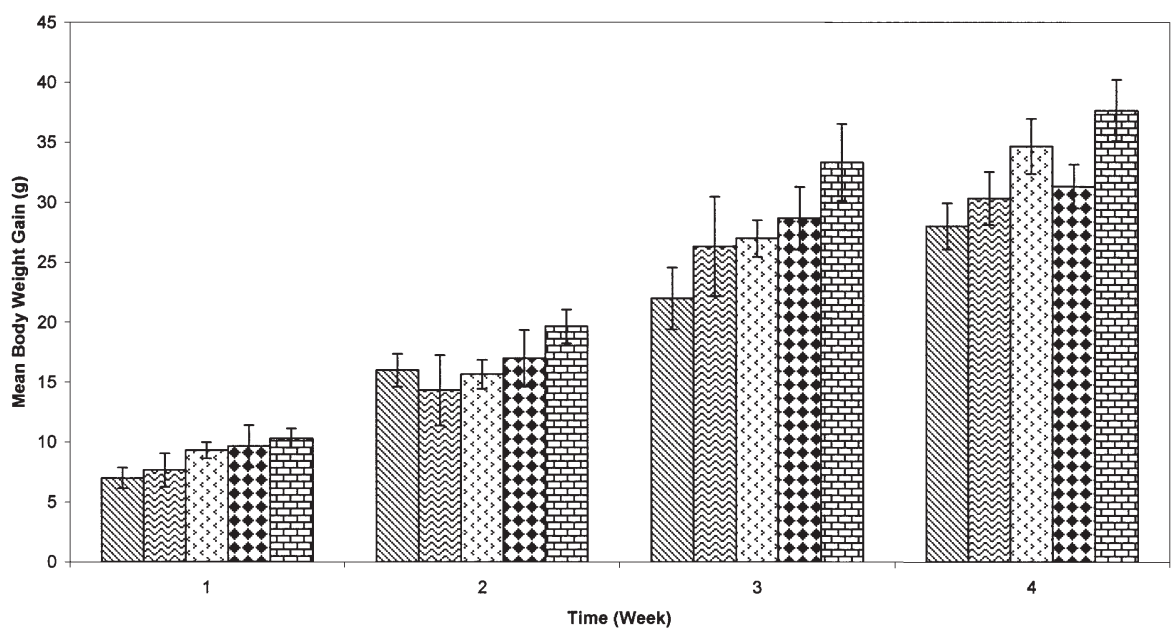

\$SO 0 SO+SPL at $5 \%$ aSO+SPL at $10 \%$ SO+EPA-SPL at $5 \%$ ⿴囗十 SO+EPA-SPL at $10 \%$

Fig. 1 Mean Body Weight Gain of the Rats Fed Soybean Oil (SO), SO blended with Soyphospholipid (SPL) at the Level of $5 \%$ and $10 \%$ and SO Blended with EPA-Containing SPL (EPA-SPL) at the Level of $5 \%$ and $10 \%$ at the end of Different Weeks.

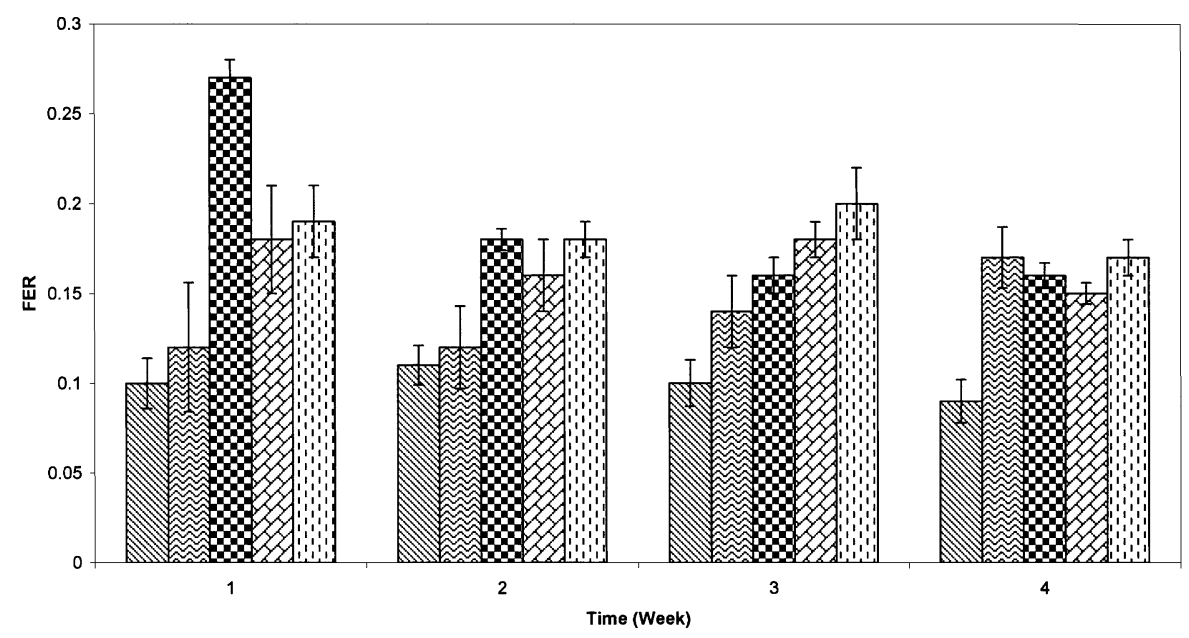

QSO $₫ S O+S P L$ at $5 \%$ SO+SPL at $10 \%$ घSO+EPA-SPL at $5 \%$ एSO+EPA-SPL at $10 \%$

Fig. 2 Food Efficiency Ratio (FER) of the Rats Fed Soybean Oil (SO), SO Blended with Soyphospholipid (SPL) at the Level of 5\% and 10\% and SO Blended with EPA-Containing SPL (EPA-SPL) at the Level of $5 \%$ and $10 \%$ at the End of Different Weeks.

soyphospholipid at $5 \%$ level when compared with rats fed soybean oil blended with soyphospholipid alone at 5\% level. There is significant decrease in TC, TG, VLDL, LDL and significant increase in HDL among the rats fed soybean oil blended with EPA containing soyphospholipid at $10 \%$ level when compared with the rats fed soybean oil blended with soyphospholipid at 10\% level.

\section{DISCUSSION}

The purpose of the present study was to obtain an idea about the dietary effect of EPA containing soyphospholipid in comparison with that of the original soyphospholipid from soybean oil admixed with soybean oil. Although no significant change in weight gain and FER between the two experimental rat groups at 5\% or 10\% level, could be noted, there was indication however of significant differences in the lipid profile. The TG level decreased signifi- 
Table 2 Lipid Concentrations of Serum of the Rats Fed Soybean Oil, Soybean Oil with Soyphospholipid at 5\% and 10\% Level and Soybean Oil with EPA Containing Soyphospholipid at 5\% and 10\% Level.

\begin{tabular}{|lccccc|}
\hline Dietary Fat Groups & $\begin{array}{c}\text { Total Cholesterol } \\
(\mathrm{mg} / \mathrm{dl})\end{array}$ & $\begin{array}{c}\text { Triglyceride } \\
(\mathrm{mg} / \mathrm{dl})\end{array}$ & $\begin{array}{c}\text { HDL-Cholesterol } \\
(\mathrm{mg} / \mathrm{dl})\end{array}$ & $\begin{array}{c}\text { VLDL-Cholesterol } \\
(\mathrm{mg} / \mathrm{dl})\end{array}$ & $\begin{array}{c}\text { LDL-Cholesterol } \\
(\mathrm{mg} / \mathrm{dl})\end{array}$ \\
\hline Soybean Oil & $52.74 \pm 2.06$ & $89.93 \pm 2.95$ & $27.87 \pm 2.44$ & $17.98 \pm 0.59$ & $8.54 \pm 1.09$ \\
$\begin{array}{l}\text { Soybean Oil With } \\
\text { Soyphospho lipid at } \\
5 \% \text { level }\end{array}$ & $50.45 \pm 1.46^{\mathrm{a}}$ & $78.41 \pm 6.91^{\mathrm{a}}$ & $29.416 \pm 1.06^{\mathrm{a}}$ & $15.68 \pm 1.38^{\mathrm{a}}$ & $5.35 \pm 1.07^{\mathrm{a}}$ \\
$\begin{array}{l}\text { Soybean Oil With } \\
\text { Soyphospho lipid at } \\
10 \% \text { level }\end{array}$ & $53.27 \pm 0.92^{\mathrm{a}}$ & $85.75 \pm 3.65^{\mathrm{a}}$ & $26.70 \pm 0.88^{\mathrm{a}}$ & $17.15 \pm 0.73^{\mathrm{a}}$ & $9.42 \pm 1.89^{\mathrm{a}}$ \\
$\begin{array}{l}\text { Soybean Oil with } \\
\text { EPA containing }\end{array}$ & $47.82 \pm 1.60^{\mathrm{b}}$ & $59.19 \pm 4.54^{* \mathrm{~b}}$ & $30.25 \pm 1.36^{\mathrm{b}}$ & $13.25 \pm 1.57^{\mathrm{b}}$ & $4.16 \pm 0.68^{\mathrm{b}}$ \\
$\begin{array}{l}\text { Soyphospho lipid at } \\
5 \% \text { level }\end{array}$ & & & & & \\
$\begin{array}{l}\text { Soybean Oil with } \\
\text { EPA containing }\end{array}$ & $47.44 \pm 1.35^{* * \mathrm{~b}}$ & $51.70 \pm 2.30^{* * * \mathrm{~b}}$ & $33.37 \pm 1.66^{* * \mathrm{~b}}$ & $10.34 \pm 0.46^{* * * \mathrm{~b}}$ & $4.22 \pm 0.39^{* \mathrm{~b}}$ \\
$\begin{array}{l}\text { Soyphospho lipid at } \\
10 \% \text { level }\end{array}$ & & & & & \\
\hline
\end{tabular}

Values are mean \pm S.E.M, $\mathrm{n}=6$

${ }^{\text {a }}$ Control group fed soybean oil Vs soybean oil with soyphospholipid at $5 \%$ and $10 \%$ level

${ }^{\mathrm{b}}$ Control group fed soybean oil with soyphospholipid at 5\% and 10\% level Vs soybean oil with EPA containing soyphospholipid at 5\% and $10 \%$ level

${ }^{*} \mathrm{p}<0.05,{ }^{* *} \mathrm{p}<0.01,{ }^{* * *} \mathrm{p}<0.001$

cantly in the case of rats fed EPA containing soyphospholipid at 5\% level when compared with the rats fed soyphospholipid without EPA content at also 5\% level. The trend of lowering of TG in serum with dietary EPA soyphospholipid thus resembled the trend of EPA containing fish oil.

There was significant decrease in TC, TG, VLDL and LDL and also significant increase in HDL level when compared between soyphospholipid group without EPA and the EPA modified soyphospholipid at 10\% level. Hypotriacylglycerolidemic effect of EPA may be attributed to sudden increase in mitochondrial fatty acid oxidation ${ }^{19-25)}$. Phospholipids reportedly reduce the cholesterol amount by transfer into bile due to unique surface active property of phospholipid. In the present study the addition of soyphospholipid in dietary soybean oil at 5\% or 10\% level did neither reduce the proportion of TC, TG, LDL, VLDL and nor did increase HDL level. The reduction in the proportions of TC, TG, LDL, VLDL and increase in HDL amount with dietary EPA soyphospholipid may be attributed to the alteration in surface active property such as interfacial tension of soyphospholipid. The interfacial tension of soyphospholipid was found to be 17.6 dynes/cm while that of the EPA containing soyphospholipid was 13.1 dynes $/ \mathrm{cm}$ when measured against water at $27^{\circ} \mathrm{C}$ using chloroform solution of $0.4 \%$ phospholipid ${ }^{26}$. The lowering of interfacial tension in the case of EPA product presumably promoted the transfer of cholesterol to bile to a greater extent thereby reducing the TC, TG, VLDL, LDL levels and increasing the HDL level.

To our knowledge the present work appears as the only investigation carried out so far pertaining to the dietary effect of EPA containing soyphospholipid and that the work points out that EPA containing soyphospholipid may be a choice in preference to soyphospholipid as a dietary phospholipid for achieving hypolipidemic effects.

\section{CONCLUSION}

EPA containing soyphospholipid is more beneficial as a hypocholesterolemic and hypotriacylglycerolidemic agent than that of the soyphospholipid at the same level (10\% $\mathrm{w} / \mathrm{w})$ along with soybean oil keeping the EFAs namely linoleic (18:2) and $\alpha$-linolenic (18:3) acids in the diets. 


\section{S. Dasgupta and D.K. Bhattacharyya}

\section{ACKNOWLEDGEMENT}

The study was financially supported by University Grants Commission (Government of India).

\section{References}

1. Bailey, Lecithins in industrial oil and fat products, (Swern, D. ed.). 1, Published by John Wiley and Sons, Inc, New York. pp.369-370 (1979).

2. Ghosh, M; Bhattacharyya, D.K. Soylecithin monoester interchange reaction by microbial lipase. J. Am. Oil Chem. Soc. 74, 761-763 (1997).

3. Mutua, L.N.; Akoh, C. Lipase catalyzed modification of phospholipids: Incorporation of n-3 fatty acids into biosurfactants. J.Am. Oil Chem. Soc. 70, 125-128 (1993).

4. Brockerhoff, H.; Schmidt, P.C.; Fong, J.W.; Tirri, L.J. Introduction of labelled fatty acid in position-1 of phosphoglycerides. Lipids 11, 421-422 (1976).

5. Totani, Y; Hara, S. Preparation of polyunsaturated phospholipids by lipase-catalyzed transesterfication. $J$. Am. Oil Chem. Soc. 68, 848-851 (1991).

6. Na, A.; Eriksson, C.; Eriksson, S. G.; Osterberg, E.; Holmberg, K. Synthesis of phosphatidylcholine with (n3) fatty acids by phospholipase $\mathrm{A}_{2}$ in microemulsion. $J$. Am. Oil Chem. Soc. 67, 766-770 (1990).

7. Magret, V.; Elkhalil, L.; Nazih-Sanderson, F.; Martin, F.; Bourre, J.M.; Fruchart, J.C.; Delbart, C. Entry of polyunsaturated fatty acids into the brain: Evidence that high density lipoprotein induced methylation of phosphatidylethanolamine and phospholipase $\mathrm{A}_{2}$ are involved. Biochem. J. 316, 805-811 (1996).

8. Yoshimoto, T.; Nakata, M.; Yamaguchi, S.; Funada, T.; Saito, Y:Inada, Y. Synthesis of eicosapentaenoyl phosphatidylcholines by polyethelene glycol-modified lipase in benzene. Biotechnol. Lett. 8, 771-775 (1986).

9. Harnas, C.; Perrin, J.L. Gram-scale preparative HPLC of phospholipids from soybean lecithins. J. Am. Oil Chem. Soc. 68, 804-808 (1991).

10. Metcalfe, L.D.; Schmitz, A.A. The rapid preparation of fatty acid esters for gas chromatographic analysis. Anal. Chem. 33, 363-364 (1961).

11. Ray, S.; Bhattacharyya, D.K. Comparative nutrition study of enzymatically and chemically interesterified palm oil products. J. Am. Oil. Chem. Soc. 72, 327-330 (1995).

12. Joanes, J. H.; Foster, C.A Salt mixture for use with basal diet either low or high in phosphorus. J. Nutr. 24, 245-256 (1942).

13. Allain, C.C.; Poon, L.S.; Chan, C.S.G.; Richmond, W.; Fu, P.C. Enzymatic determination of total serum cholesterol. Clin. Chem. 20, 470-475 (1974).

14. Warnick, G.R.; Nguyen, T.; Albers, A. Comparison of improved methods for quantification of high-density lipoprotein. Clin. Chem. 31, 217-222 (1985).

15. Friedwald, W.T.; Levy, R.I.; Fredrickson, D.S. Estimation of the concentration of low density lipoprotein cholesterol in plasma without use of preparative ultracentrifuge. Clin. Chem. 18, 499-502 (1972).

16. Hatch, F.T.; Lees, R.S. Practical methods for plasma lipoprotein analysis. Adv. Lipid Res. 6, 1-68 (1968).

17. Bucolo, G.; David, M. Quantitative determination of serum triglyceride by the use of enzymes. Clin. Chem. 19, 476-482 (1973).

18. Biometrica tables for statisticians, 1, (Pearson, S.; Hartley, H.O. ed.), Cambridge (1966).

19. Wong, S. H.; Nestel, P.J.; Trimble, R.P.; Stores, G.B.; Illmann, R.J.; Topping, D. L. The adaptive effects of dietary fish and safflower oil on lipid and lipoprotein metabolism in perfused rat liver. Biochim. Biophys. Acta. 792, 103-109 (1984).

20. Nossen, J.Ø.; Rustan, A.C.; Gloppestad, S.H.; Målbakken, S.; Drevon, C.A. Eicosapentaenoic acid inhibits synthesis and secretion of triacylglycerols by cultured rat hepatocytes. Biochim. Biophys. Acta. 792, 56-65 (1986).

21. Rustan, A.C.; Nossen, J.Ø.; Christiansen, E.N.; Drevon, C.A. Eicosapentaenoic acid reduces hepatic synthesis and secretion of triacylglycerol by decreasing the activity of acyl-coenzyme A: 1,2-Diacylglycerol acyltransferase. J. Lipid Res. 29, 1417-1426 (1988).

22. Rustan, A.C.; Christiansen, E.N.; Drevon, C.A. Serum lipids, hepatic glycerolipid metabolism and peroxisomal fatty acid oxidation in rats fed $\omega$-3 and $\omega$-6 fatty acids. Biochem. J. 283, 333-339 (1992).

23. Sebokova, E.; Klimes, I.; Hermann, M.; Minchenko, A.; Mitkova, A.; Hromadova, M. Modulation of the hypolipidemic effect of fish oil by inhibition of adipose tissue lipolysis with acipimox, A nicotinic acid Analog. Ann. NY Acad. Sci. 683, 183-191 (1993).

24. Brown, A.M.; Baker, P.W.; Gibbson, G.F. Changes in fatty acid metabolism in rat hepatocytes in response to dietary n-3 fatty acids are associated with changes in the intracellular metabolism and secretion of apolipoprotein B-48. J. Lipid. Res. 38, 469-481 (1997).

25. Harris, W.; Lu, G.; Rambjør, G.S.; Walen, A.I.; Ontko, J.A.; Cheng, Q.; Windsor, S.L. Influence of n-3 fatty acid supplementation on the endogenous activities of plasma lipases. Am. J. Clin. Nutr. 66, 254-260 (1997).

26. Nandi, S. Studies on processing of some refinery byproducts for better utilisation. PhD thesis. University of Calcutta. p.169 (2005). 